This is the peer reviewed version of the following article: Rama, G., Ardá, A., Maréchal, J., Gamba, I., Ishida, H., Jiménez-Barbero, J., Vázquez, M. E. and Vázquez López, M. (2012), Stereoselective Formation of Chiral Metallopeptides. Chem. Eur. J., 18: 7030-7035, which has been published in final form at https://doi.org/10.1002/chem.201201036.

This article may be used for non-commercial purposes in accordance with Wiley Terms and Conditions for Use of Self-Archived Versions 


\title{
Stereoselective formation of chiral metallopeptides
}

\author{
Gustavo Rama, ${ }^{[a]}$ Ana Ardá, ${ }^{[b]}$ Jean-Didier Maréchal, ${ }^{[c]}$ Ilaria Gamba, ${ }^{[a]}$ Hitoshi Ishida, ${ }^{[\mathrm{d}, \mathrm{e}]}$ Jesús \\ Jiménez-Barbero, ${ }^{[\mathrm{b}]}$ M. Eugenio Vázquez ${ }^{*[\mathrm{ff}]}$ and Miguel Vázquez López ${ }^{*[\mathrm{a}]}$
}

Despite the enormous growth of chemical biology over the last decade, the contributions of coordination and metallosupramolecular chemistry in this area remain relatively scarce ${ }^{[1]}$ One possible reason for this underdevelopment is that the chemical differences between biomolecules and typical ligands hamper the integration of metal complexes into biological systems. ${ }^{[2]}$ In this context, peptides could be particularly attractive templates for the design of biologically friendly coordination compounds that integrate precise structural and biofunctional properties encoded by the amino acid sequence of the peptide ligands. ${ }^{[3]}$ Furthermore, the stereoselective formation of chiral complexes is of fundamental interest in chemical biology, as chirality plays a major role in the recognition processes of biological target, ${ }^{[4,5]}$ but controlling the metal center configuration usually requires demanding synthetic procedures for obtaining chiral ligands, ${ }^{[6,7,8]}$ which complicates the access to multiple

[a] Departamento de Química Inorgánica and Centro Singular de Investigación en Química Biolóxica e Materiais Moleculares (CIQUS) Universidade de Santiago de Compostela, 15782 Santiago de Compostela (Spain)

Fax: (+34) 981591012 .

E-mail: miguel.vazquez.lopez@usc.es

[b] Department of Chemical and Physical Biology CIB-CSIC, 28040 Madrid (Spain)

Fax: (+34)915360432

E-mail: jjbarbero@cib.csic.es

[c] Departament de Química

Universitat Autònoma de Barcelona, 08193 Cerdanyola (Spain)

[d] Department of Chemistry, Graduate School of Science Kitasato University, 1-15-1 Kitasato, Minami-ku, Sagamihara, Kanagawa 252-0373 (Japan)

[e] Precursory Research for Embryonic Science (PRESTO) Japan Science and Technology Agency (JST). 4-1-8 Honcho, Kawaguchi, Saitama 332-0012 (Japan)

[f] Departamento de Química Orgánica and Centro Singular de Investigación en Química Biolóxica e Materiais Moleculares (CIQUS) Universidade de Santiago de Compostela, 15782 Santiago de Compostela, (Spain) Fax: (+34) 981591012.

E-mail: eugenio.vazquez@usc.es

Supporting information for this article is available on the WWW under http://www.chemeurj.org/ or from the author.

structural variants that are required for the systematic studies involved in the optimization of their biological properties.
Peptides however, being intrinsically chiral, are ideal platforms for controlling the configuration of their derived asymmetric metal complexes. In addition to that, the fast and robust solid phase peptide synthesis (SPPS) methods allow their assembly and optimization with a simplicity and flexibility unmatched by classic organic synthetic procedures in solution. ${ }^{[9]}$

Metalloproteins exploit the protein architecture to carefully position the amino acid side chains in order to create appropriate coordination environments ${ }^{[10]}$ This can also be achieved in synthetic molecules by using unnatural metal-chelating amino acids that simultaneously orient more than one donor atom. Thus, it is known that the 2,2'-bipyridine (Bpy) ligand leads to stable complexes with many metal ions and as such, it is one of the most commonly used binding units in coordination and supramolecular chemistry. ${ }^{[11]}$ However, there are still very few examples of bipyridine-based metallopeptides in the literature. In most reports the Bpy units are attached to the N-terminal end of the peptide sequence, ${ }^{[12]}$ or located at the side chain of an unnatural amino acid, ${ }^{[13]}$ but there are only a handful of examples in which the Bpy units are incorporated as part of the peptide backbone. ${ }^{[14]}$

Herein we report a straightforward approach to control the chirality or peptide metal complexes. Our strategy takes advantage of standard SPPS methodsfor fast and efficient access to simple linear Bpy-based peptide ligands, and exploits the strong coupling between the conformational preferences of the peptide chain with the coordination geometry of the metal centres to control of the configuration of the resulting peptide complexes.

The Bpy unit was derivatized with 5-amino-3-oxapentanoic acid (O1Pen) as a Fmoc-protected achiral amino acid for solid phase peptide synthesis (Fmoc-O1PenBpy-OH 5). Starting from the commercial 5,5'-dimethy-2,2'-bipyridine 1, and following a modified procedure from earlier reports, ${ }^{[14 a, 15]}$ we were able to design and optimize the synthesis of $\mathbf{5}$ in multigram scale with an overall yield of $46 \%$. In short, after initial oxidation and esterification, the Bpy was desymmetrized by taking advantage of the poor solubility of its monocarbohydrazide (2). Curtius rearrangement of the corresponding carbazide, and subsequent deprotection of intermediate $\mathbf{3}$, afforded the desired Bpy amino acid core unit 4 . Given the poor reactivity of aromatic amines in peptide couplings, ${ }^{[14 a, 16]}$ the core Bpy amino acid $\mathbf{4}$ was coupled with 5-amino-3-oxapentanoic acid (O1Pen) to give the desired final building block (5 Scheme 1), which displayed good 
solubility and reactivity for performing solid phase coupling reactions under standard conditions.
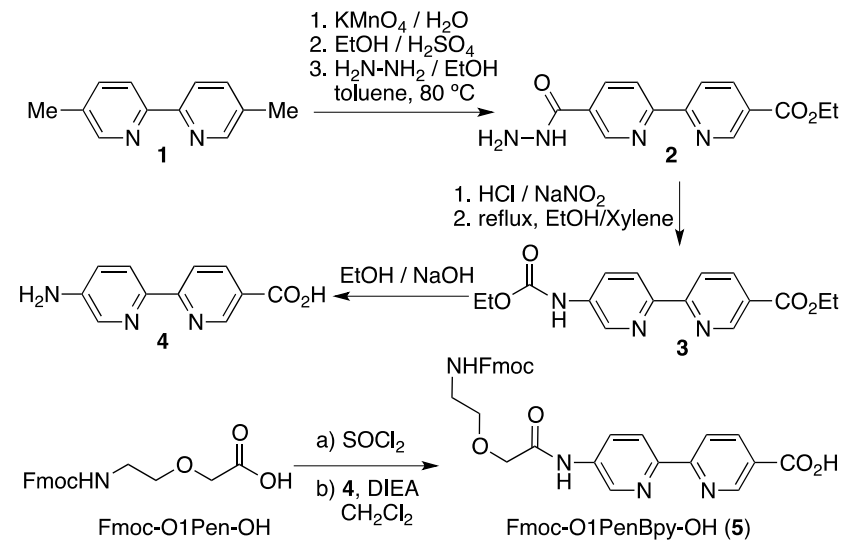

Scheme 1. Synthesis of the 2,2'-bipyridine amino acid (4), and its derivative for SPPS, Fmoc-O1PenBpy-OH (5).

Following the synthesis of $\mathbf{5}$, and based on preliminary molecular modeling studies, $\left[{ }^{17}\right]$ we designed a number of peptide ligands featuring two Bpy coordinating units joined by short linkers containing between 3 and 5 amino acid residues (Table 1, $\left.\mathbf{P}^{\mathbf{3}}-\mathbf{P}^{\mathbf{5}}\right)$. These include a Pro-Gly $\beta$-turn promoting sequence that would preorganize the peptide chain and promote metal chelation, thus avoiding the formation of polymeric peptide complexes in the presence of metal ions. ${ }^{[18]}$ In addition to the conformational restrictions imposed by the Pro residue, we expected that introducing D-Pro or L-Pro residues for the synthesis of enantiomeric peptide ligands would allow the control the chirality of the resulting metal complexes. Peptides were synthesized following standard Fmoc/tBu solid-phase protocols, ${ }^{[14 b, c, 19]}$ and purified by reverse-phase HPLC.

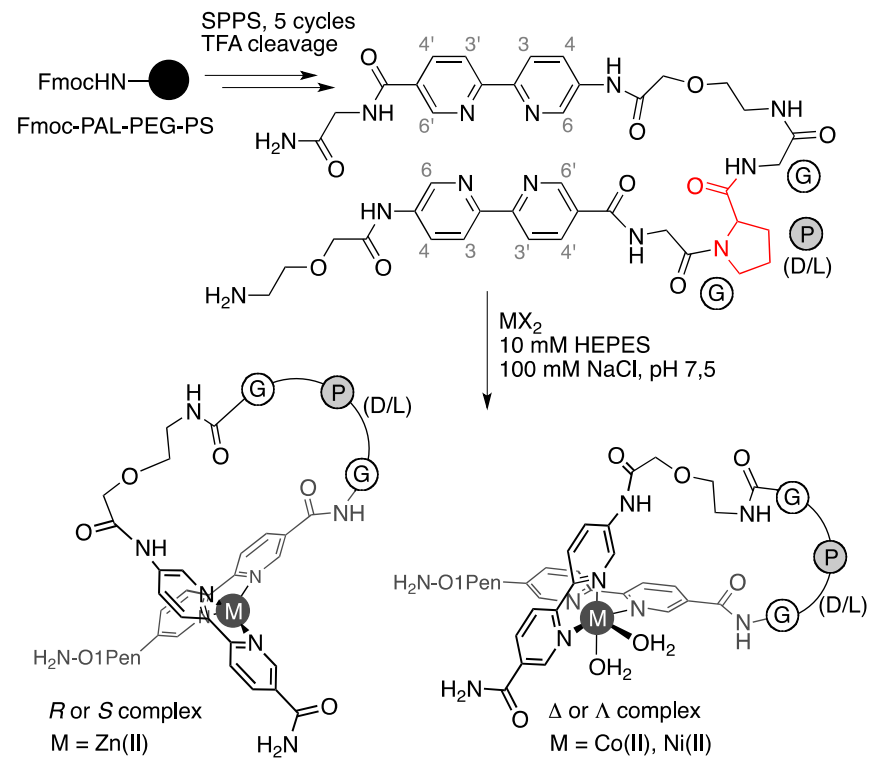

Incubation of $13 \mu \mathrm{M}$ solutions of the three L-peptide ligands $\left(\mathbf{L}-\mathbf{P}^{\mathbf{3}}, \mathbf{L}-\mathbf{P}^{\mathbf{4}}, \mathbf{L}-\mathbf{P}^{\mathbf{5}}\right)$ in PBS buffer $(\mathrm{pH}=5.6,298 \mathrm{~K})$ with $\mathrm{Co}(\mathrm{II})$ resulted in clear bathochromic shifts of the Bpy absorption band due to the complexation processes, from $309 \mathrm{~nm}$ in the free ligands to $322 \mathrm{~nm}$ in their metal complexes. The spectroscopic changes displayed by the three peptides upon incubation under the same conditions with $\mathrm{Ni}(\mathrm{II})$, which has higher tendency than $\mathrm{Co}$ (II) to form octahedral complexes, and with $\mathrm{Zn}$ (II), which forms diamagnetic complexes suitable for perform NMR studies in solution, were qualitatively very similar to those observed for Co(II).

Table 1. Peptide ligands synthesized in this study.

\begin{tabular}{|c|c|}
\hline Peptide ${ }^{[a]}$ & Sequence \\
\hline $\mathbf{L}-\mathbf{P}^{3}$ & H-O1PenBpy-Gly-L-Pro-Gly-O1PenBpy-Gly-NH ${ }_{2}$ \\
\hline D-P $\mathbf{P}^{3}$ & H-O1PenBpy-Gly-D-Pro-Gly-O1PenBpy-Gly-NH \\
\hline L-P $\mathbf{P}^{4}$ & H-O1PenBpy-Gly-Gly-L-Pro-Gly-O1PenBpy-Gly-NH \\
\hline $\mathbf{L}-\mathbf{P}^{5}$ & H-O1PenBpy-Gly-Gly-Gly- L-Pro -Gly-O1PenBpy-Gly- $\mathrm{NH}_{2}$ \\
\hline
\end{tabular}

[a] Loop sequences are highlighted in italics. All peptides were synthesized as Nterminal free amine and C-terminal amide.

Table 2. Stability constants of peptides $\mathbf{L}-\mathbf{P}^{\mathbf{3}}, \mathbf{L}-\mathbf{P}^{4}, \mathbf{L}-\mathbf{P}^{5}$ complexes with selected metal ions in PBS, pH 5.6 at $298 \mathrm{~K}$.

\begin{tabular}{|c|c|c|c|c|}
\hline Peptide & $\log \beta_{m, n}^{[a]}$ & $\mathrm{Co}(\mathrm{II})$ & $\mathrm{Ni}(\mathrm{II})$ & $\mathrm{Zn}(\mathrm{II})$ \\
\hline \multirow{2}{*}{ L-P ${ }^{3}$} & $\log \beta_{11}$ & $7.16(0.15)$ & $6.51(0.05)$ & $6.23(0.11)$ \\
\hline & $\log \beta_{12}$ & $11.92(0.39)$ & $11.95(0.13)$ & $11.08(0.33)$ \\
\hline \multirow{2}{*}{ L-P ${ }^{4}$} & $\log \beta_{11}$ & $6.75(0.05)$ & $6.51(0.03)$ & $6.08(0.05)$ \\
\hline & $\log \beta_{12}$ & $11.87(0.14)$ & $11.91(0.08)$ & $11.74(0.13)$ \\
\hline \multirow{2}{*}{ L-P $\mathbf{P}^{5}$} & $\log \beta_{11}$ & $5.18(0.25)$ & $6.02(0.04)$ & $3.33(1.15)$ \\
\hline & $\log \beta_{12}$ & $11.79(0.33)$ & $11.97(0.10)$ & $8.87(0.23)$ \\
\hline
\end{tabular}

[a] Loop sequences are highlighted in italics. All peptides were synthesized as Nterminal free amine and C-terminal amide.

The binding constants derived from the UV/vis titrations are summarized in Table 2, and indicate that the Co(II) complex with $\mathbf{L}-\mathbf{P}^{\mathbf{3}}$ is the most stable of the series $\left(\log \beta_{11}=7.16\right)$. Interestingly, the best fit to the experimental data suggests an appreciable proportion of the 1:2 $\mathrm{ML}_{2}$ species in the initial steps of the titration, when the peptide ligand is in greater excess over the metal ion. Further increasing in the metal to ligand ratios, progressively shifts the equilibrium towards the expected $1: 1$ complex later in the titration (Figure 1). 


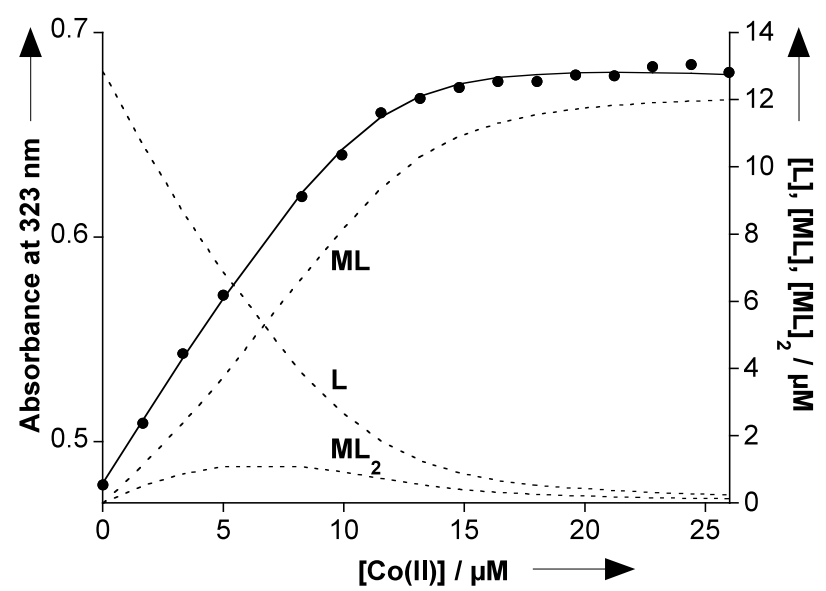

Figure 1. UV/Vis titration of $13 \mu \mathrm{M} \mathrm{L}-\mathbf{P}^{3}$ with increasing concentrations of Co(II) and best fit to a mixed 1:1 and 1:2 model (solid line). Curves representing the relative populations of free $\mathbf{L}-\mathbf{P}^{3}(\mathrm{~L}), \mathrm{ML}$ and $\mathrm{ML}_{2}$ complexes are overlaid as dashed lines.

The thermodynamic stabilities of the $\mathrm{Ni}(\mathrm{II})$ and $\mathrm{Zn}(\mathrm{II})$ complexes of $\mathbf{L}-\mathbf{P}^{3}$ are about one order of magnitude less stable than the $\operatorname{Co}(\mathrm{II})$ equivalent $\left(\log \beta_{11} \approx 6.75-6.08\right)$. The L-P $\mathbf{P}^{4}$ metal complexes appear only marginally less stable than their $\mathbf{L}-\mathbf{P}^{3}$ analogs but, in contrast, all the $\mathbf{L}-\mathbf{P}^{\mathbf{5}}$ metallopeptides display significantly lower binding constants $\left(\log \beta_{11} \approx 5.18-3.33\right)$. Moreover, the titration profiles of the $\mathbf{L}-\mathbf{P}^{\mathbf{5}}$ peptides suggest the occurrence of higher order species and/or oligomers. Finally, in addition to these titrations, the absence of $\mathrm{d}-\mathrm{d}$ transition bands in concentrated solutions of $\mathbf{L}-\mathbf{P}^{3}$ with $\mathrm{Ni}(\mathrm{II})$ and $\mathrm{Co}(\mathrm{II})$ suggest that these metals adopt an octahedral configuration as $[\mathrm{M}(\mathrm{L}-$ $\left.\left.\mathbf{P}^{3}\right)\left(\mathrm{H}_{2} \mathrm{O}\right)_{2}\right]^{2+}$ species, completing their coordination sphere with two water molecules.

Given the renewed significance of chiral coordination complexes with biological applications, ${ }^{[5]}$ we were thus particularly interested in the effect of the chiral D-Pro and L-Pro residues included in the peptide loops. Considering that $\mathbf{L}-\mathbf{P}^{3}$ and $\mathbf{L}-\mathbf{P}^{4}$ form coordination compounds of similar thermodynamic stabilities, we decided to focus our attention on the $\mathbf{L}-\mathbf{P}^{3}$ peptide, because the shorter three-amino acid loop in this ligand should impose tighter conformational restrictions than $\mathbf{L}-\mathbf{P}^{4}$, and hence provide with better chiral induction in the resulting metallopeptides.

At this point, we decided to carry out molecular modeling studies in order to gain some insight into the structural features of the $\left[\mathrm{Zn}\left(\mathbf{L} / \mathbf{D}-\mathbf{P}^{3}\right)\right]^{2+}$ complexes and identify the relationship between the chirality of the Pro residue and that of the resulting metal complex. ${ }^{[20]}$ It has to be noted that the modeling of metalmediated recognition processes is still one of the major challenges faced by computational chemistry, ${ }^{[21]}$ and there are no reports of reliable models of metal complexes derived of highly flexible ligands, a tool which could be very useful in metallosupramolecular chemistry or in inorganic chemical biology. In order to determine the structure of both complexes, and because of the presence of non-natural residues, we designed and applied a first principle protocol instead of knowledge-driven and fragment-based approaches recently reported. ${ }^{[22]}$ Calculations were first undertaken to characterize the conformational space of the isolated ligands. Large torsional Monte Carlo samplings coupled with low energy mode displacements were carried out for both D- and L-Pro species. ${ }^{[23]}$ In each case, about 250 minima were identified in a window of about $21 \mathrm{~kJ} \cdot \mathrm{mol}^{-1}$. The conformers presented similar overall tendencies in both ensembles, and could be clustered into a reduced number of folds. In most, substantial $\pi-\pi$ interactions between the two Bpy units were observed (see Figure S1, supporting information), and the lowest energy conformations presented stronger stacking. Despite some variability, the Gly ${ }^{1}$-Pro-Gly ${ }^{2}$ loop mainly adopts a turn with a hydrogen bond between the carbonyl of the Pro and the nitrogen of the $\mathrm{Gly}^{2}$ backbone. Importantly, the asymmetry arising from the D-Pro and L-Pro residues appears in the lowest energy conformations as a loop in an anti-clockwise configuration for the former and a clockwise configuration for the latter.

The structures of the $\mathrm{Zn}(\mathrm{II})$ complexes were obtained by a constrained minimization of the lowest energy conformation of the isolated ligands towards a tetrahedral geometry of the nitrogens in the bipyridine groups ${ }^{[24]}$ followed by a Quantum Mechanical/Molecular Mechanics minimization of the zinc-bound complexes (see supplementary information) using the ONIOM scheme ${ }^{[25]}$ as implemented in Gaussian'09. ${ }^{[26]}$ In all the resulting structures the $\pi-\pi$ interactions have been lost, so that the two Bpy units are almost perpendicular, the twist of the Gly ${ }^{1}-\mathrm{Pro}-\mathrm{Gly}^{2}$ loop has been amplified, and the Pro-Gly ${ }^{2}$ hydrogen bonding has been significantly lost. Importantly, the optimized structure of the DPro and L-Pro systems appear highly symmetric with the metal center providing with $R$ and $S$ chirality, respectively (Figure 2). Moreover, attempts to obtain inverted metal configurations based on alternative low-energy conformations of the ligand were in all cases unsuccessful.
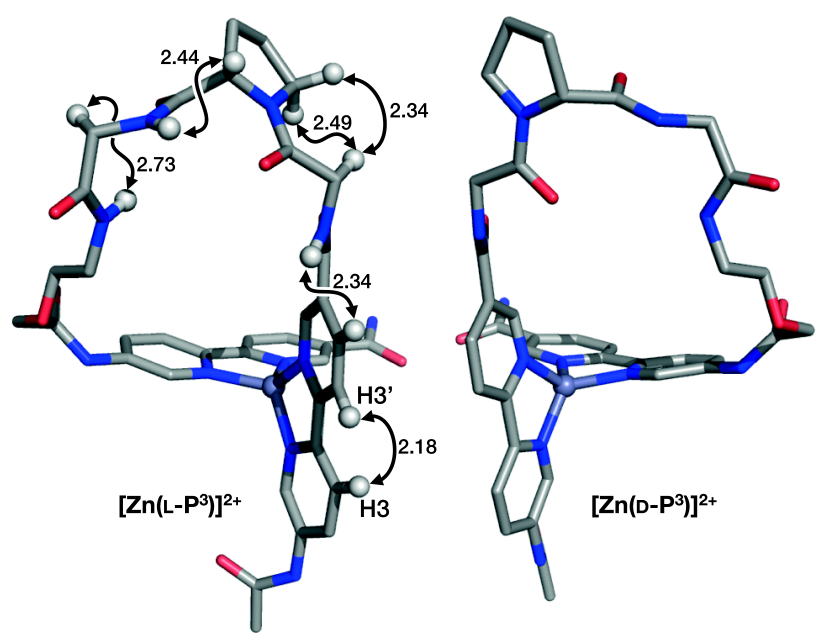

Figure 2. Optimized structures of the $\left[\mathrm{Zn}\left(\mathbf{L} / \mathbf{D}-\mathbf{P}^{3}\right)\right]^{2+}$ complexes. The arrows indicate the NOE contacts observed in the NOESY spectrum of $\left[\mathrm{Zn}\left(\mathbf{L}-\mathbf{P}^{3}\right)\right]^{2+}(600 \mathrm{MHz}$, $\mathrm{H}_{2} \mathrm{O} / \mathrm{D}_{2} \mathrm{O}$ PBS buffer, $\mathrm{pH} 5.6,280 \mathrm{~K}, 500 \mathrm{~ms}$ mixing time) in the presence of 1.2 equivalents of $\mathrm{ZnSO}_{4}$, which are not present without the salt.

Further comparison between the free and metal-bound systems show that the conformations adopted by the ligands in the complexes are relatively close to the conformations of the free ligands in the $21 \mathrm{~kJ} / \mathrm{mol}$ window from the absolute minima (with rmsd lower than $1 \AA$ ). The conformational transition of the ligands between unbound and bound structures only requires the rearrangement of one of the Bpy units, for which the twist of the 
loop is accentuated (Figure S1, supporting information). Our results show that the chirality of the Pro residue dictates a highly asymmetric conformational space of the ligands. This leads to the preorganization of the ligands towards conformations that apparently condition the chirality of the metal bound systems. ${ }^{[27]}$

$\mathrm{Zn}$ (II) complexes are diamagnetic and thus suitable for NMR studies. This allowed us to make a complete NMR characterization of $\left[\mathrm{Zn}\left(\mathbf{L}-\mathbf{P}^{3}\right)\right]^{2+}$ in order to validate in solution the structure described above. First, the isolated ligand $\left(\mathbf{L}-\mathbf{P}^{\mathbf{3}}\right)$ was studied $\left(0.2 \mathrm{mM}\right.$ in $\mathrm{D}_{2} \mathrm{O}$ PBS buffer at $\left.\mathrm{pH}=5.6\right) .{ }^{1} \mathrm{H}$ NMR spectral assignment (TOCSY, 25 and $60 \mathrm{~ms}$ mixing times, and NOESY, $500 \mathrm{~ms}$ mixing time, see supporting information) was carried out at $280 \mathrm{~K}$. The NOESY spectrum only showed the intra-ring cross peaks involving $\mathrm{H} 3$ and $\mathrm{H} 4$ protons (see supporting information) for each pyridine ring as the only NOE contact involving aromatic protons. This fact is in agreement with previous studies that excluded the presence of a cis disposition of the nitrogen atoms in 2,2'-subtituted bipyridines. ${ }^{[28]}$ Fittingly, addition of 1.2 equivalents of $\mathrm{Zn}$ (II) induced significant chemical shift changes of the aromatic protons (Figure 3, panel A), indicating a change in their chemical environments, and thus suggesting the complexation of the Bpy to the metal center. DOSY spectra (see supporting information) excluded the presence of oligomers upon these conditions. Moreover, inspection of the new NOESY spectra (in $\mathrm{H}_{2} \mathrm{O}$ and $\mathrm{D}_{2} \mathrm{O}$ ) now recorded revealed a new NOE contact in the aromatic region corresponding to an inter-ring H3-H3' contact (Figure 3, panel B). This key cross peak strongly supports the existence of a conformational change, from trans to cis, around the $\mathrm{C}-\mathrm{C}$ bond of the bipyridine moieties. Additional long range NOEs that were in full agreement with the distances estimated for the tetrahedric structure proposed by the theoretical calculations (Figure 2 and supporting information) were also found. In addition to that, cross peaks between the hydrogens in positions 6 and 6' from the two coordinating Bpy units, which would be expected for a hypothetical octahedral $\left[\mathrm{Zn}\left(\mathbf{L}-\mathbf{P}^{3}\right)\left(\mathrm{H}_{2} \mathrm{O}\right)_{2}\right]^{2+}$ complex, were not observed, further supporting the tetrahedral arrangement of the two Bpy units around the metal center. These results represent the first detailed NMR study of labile Bpy coordination compounds.

Following the structural characterization of the complexation of $\mathbf{L}-\mathbf{P}^{\mathbf{3}}$, we studied the influence of the chirality of the Pro residues by circular dichroism. The CD spectra both $\mathbf{L}-\mathbf{P}^{\mathbf{3}}$ and $\mathbf{D}-$ $\mathbf{P}^{3}$, as well as the spectra their corresponding metal complexes are qualitatively very similar with all the metal ions, and only minor variations are observed in the intensity and position of the $C D$ bands. As expected, $\mathbf{L}-\mathbf{P}^{3}$ and its enantiomer $\mathbf{D}-\mathbf{P}^{3}$ give rise to mirror image spectra, showing two bands of opposite signs at approximately 300 and $330 \mathrm{~nm}$ with a crossover at $316 \mathrm{~nm}$. D-P $\mathbf{P}^{3}$ displays a positive Cotton effect and $\mathbf{L}-\mathbf{P}^{\mathbf{3}}$ a mirror spectrum with a negative Cotton effect (Figure 3 and ESI). The intensity of these bands increases notably upon addition of metal ions, which also experiment a bathochromic shift to 315 and $340 \mathrm{~nm}$. The sign of the Cotton effect of the complexes is consistent with a $\Lambda$ configuration for the D-Pro metallopeptides $\left[\mathrm{M}\left(\mathbf{D}-\mathbf{P}^{3}\right)\left(\mathrm{H}_{2} \mathrm{O}\right)_{2}\right]^{2+}$, and $\Delta$ - configuration for the L-Pro diaquo $\mathrm{Co}(\mathrm{II})$ and $\mathrm{Ni}(\mathrm{II})$ complexes, ${ }^{[29]}$ and in agreement with the conformational preferences predicted for the peptide ligands in our computational studies.

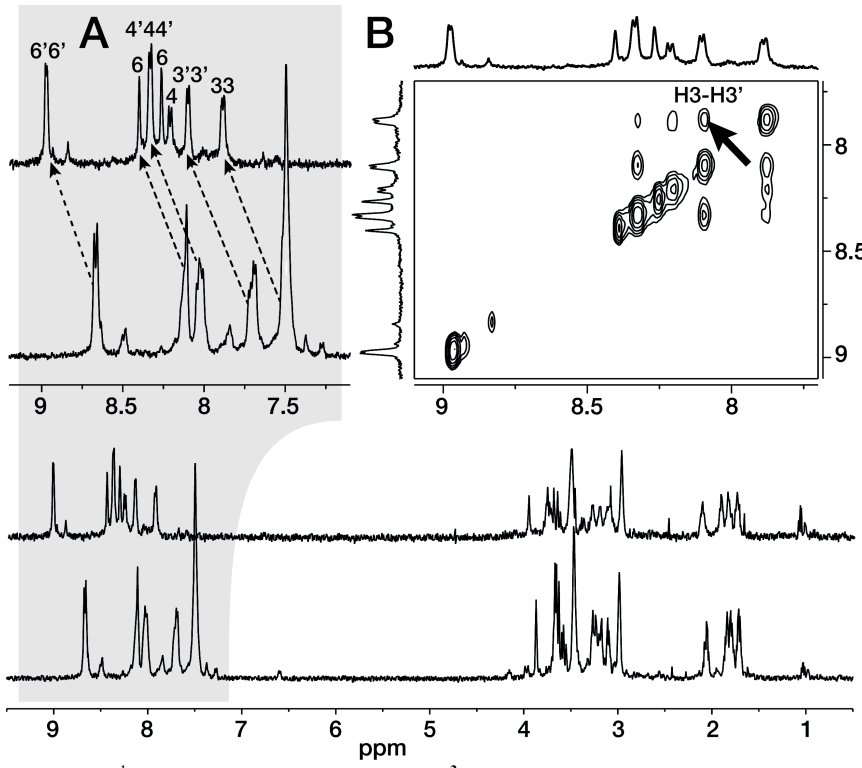

Figure 3. a) ${ }^{1} \mathrm{H}$ NMR $600 \mathrm{MHz}$ spectra of $\mathbf{L}-\mathbf{P}^{3}$ at $280 \mathrm{~K}$ in $\mathrm{D}_{2} \mathrm{O}$ (PBS buffer, pH 5.6) in the absence (bottom spectrum) and presence (top spectrum) of 1.2 equivalents of $\mathrm{Zn}$ (II) The corresponding aromatic regions are enlarged and the chemical shifts changes are annotated. b) Aromatic region of the NOESY spectrum (500 ms mixing time) at $280 \mathrm{~K}$ in the presence of 1.2 equivalents of $\mathrm{Zn}(\mathrm{II})$.

In summary, we have demonstrated a simple procedure for the thermodynamic selection of the supramolecular chirality in metallopeptide complexes, as shown by detailed theoretical and structural studies, including the first detailed NMR study of a labile Bpy coordination compound, the $\left[\mathrm{Zn}\left(\mathbf{l}-\mathbf{P}^{3}\right)\right]^{2+}$ complex. This strategy should be applicable for the synthesis of bioactive peptides with multiple coordinating units and, towards this end, ongoing efforts in our group aim at the synthesis and study of trisbipiridyl octahedral metallopeptide complexes, as well as exploiting the versatility of peptide synthesis for obtaining biofunctional complexes.

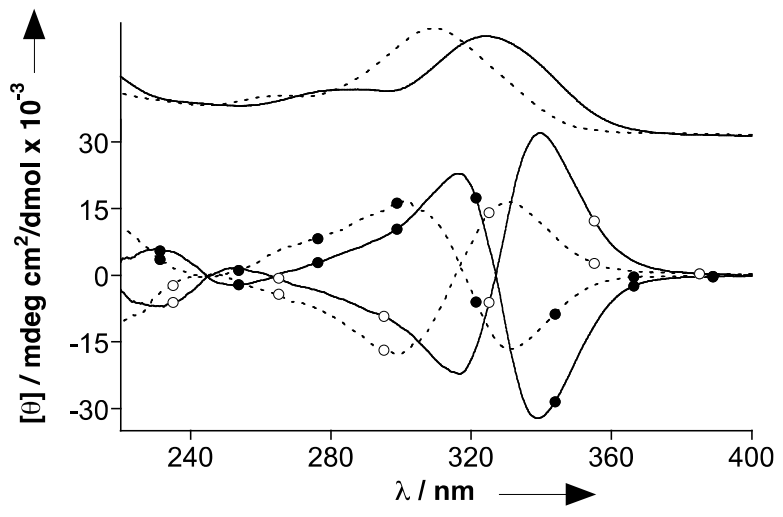

Figure 4. Dashed lines: Circular Dichroism spectra of a $0.7 \mathrm{mM}$ solution of D-P $\mathbf{P}^{\mathbf{3}}(\mathrm{O})$ and L-P $\mathbf{P}^{\mathbf{3}}(\bullet)$ in $10 \mathrm{mM}$ PBS buffer $\mathrm{pH}$ 5.1. Continuous lines: same solutions after addition of 1.3 eq. of $\mathrm{Co}(\mathrm{II})$. Absorption spectra of free (dashed line) and coordinated L-P $\mathbf{P}^{\mathbf{3}}$ (solid line) are shown for reference on top of the CD spectra.

\section{Acknowledgements}

We thank the support given by the Spanish grants CTQ2009-14431/BQU, SAF201020822-C02, SAF2007-61015, Consolider Ingenio 2010 CSD2007-00006, and the 
Xunta de Galicia INCITE09 209 084PR, GRC2010/12, PGIDIT08CSA-047209PR. H. I. thanks the financial supports by the PRESTO Program of JST and a Grant-inAid for Scientific Research (C) from the Ministry of Education, Culture, Sports, Science, and Technology (21550163). G. R. thanks the International Iberian Nanotechnology Laboratory (INL) for his PhD fellowship.

\section{Keywords: chirality $\bullet$ ligand effects $\bullet$ metallopeptides $\bullet$ NMR spectroscopy $\bullet$ molecular modelling}

[1] a) E. Meggers, Chem. Commun. 2009, 1001-1010; b) Z. Guo , P. J. Sadler, Angew. Chem. Int. Ed. 1999, 38, 1512-1531; c) T. Storr, K. H. Thompson, C. Orvig, Chem. Soc. Rev. 2006, 35, 534-544: d) K. L. Haas, K. J. Franz, Chem. Rev. 2009, 109, 4921-4960.

[2] J. E. M. Lewis, E. L. Gavey, S. A. Cameron, J. D. Crowley, Chem. Sci. 2012, 3, 778-784; b) K. L. Haas, K. J. Franz, Chem. Rev. 2009, 109, 4921-4960; c) Y. Lu, Inorg. Chem. 2006, 45, 9930-9940.

[3] a) G. Licini, P. Scrimin, Angew. Chem. Int. Ed. 2003, 42, 4572-4575; b) G. Xing, V. J. DeRose, Curr. Opin. Chem. Biol. 2001, 5, 196-200; c) M. Albercht, P. Stortz, Chem. Soc. Rev. 2005, 34, 496-506; d) M. J. Kelso, R. L. Beyer, H. N. Hoang, A. S. Lakdawala, J. P. Snyder, W. V. Oliver, T. A. Robertson, T. G. Appleton, D. P. Fairlie, J. Am. Chem. Soc. 2004, 126, $4828-4842$.

[4] a) S. W. Millwards, S. Fiacco, R. J. Austin, R. W. Roberts, ACS Chem. Biol. 2007, 2, 625-634; b) A. F. A. Peacock, J. A. Stuckey, V. L. Pecoraro, Angew. Chem. Int. Ed. 2009, 48, 7371-7374; c) D.-R. Ahn, T. W. Kim, J.-I. Hong, J. Org. Chem. 2001, 66, 5008-5011; d) R. P. Houser, M. P. Fitzsimons, J. K. Barton, Inorg. Chem. 1999, 38, 1368-1370; e) M. Albrecht, P. Stortz, R. Nolting, Synthesis 2003, 9, 1307-1320; f) L-N. Ji, X-H. Zou, J-G. Liu, Coord. Chem. Rev. 2001, 216-217, 513-536.

[5] a) S. E. Howson, A. Bolhuis, V. Brabec, G. J. Clarkson, A. R. Malina, P. Scott, Nature Chem. 2012, 4, 31-36; b) N. Ousaka, Y. Takeyama, H. Iida, E. Yashima, Nature Chem. 2011, 3, 856-861; c) A. F. A. Peacock, J. A. Stuckey, V. L. Pecoraro, Angew. Chem. Int. Ed. 2009, 48, 7371-7374.

[6] a) L. D. Caulder, K. N. Raymond, Acc. Chem. Res. 1999, 32, 975-982; b) C. Piguet, G. Bernadinelli, G. Hopfgartner, Chem. Rev. 1997, 97, 2005-2062; c) M. Albrecht, Chem. Soc. Rev. 1998, 27, 281-288; d) R. Ziessel, Inorg. Chem. 1998, 37, 4146-4148; e) A. von Zelewsky, Coord. Chem. Rev. 1999, 190192, 811-825; f) U. Knof, A. von Zelewsky, Angew. Chem. Int. Ed. 1999, 38 , $302-322$.

[7] a) P. Hayoz, A. von Zelewsky, H. Stoeckli-Evans, J. Am. Chem. Soc. 1993, 115, 5111-5114; b) L. Cardo, V. Sadovnikova, S Phongtongpasuk, N. J. Hodgesb, M. J. Hannon, Chem. Commun. 2011, 47, 6575-6577.

[8] a) Z. Lin, M. A. Celik, C. Fu, K. Harms, G. Frenking, E. Meggers, Chem. Eur. J. 2011, 17, 12602-12605; b) E. Meggers, Eur. J. Inorg. Chem. 2011, 2911-2926; c) J. Lacour, V. Hebbe-Viton, Chem. Soc. Rev. 2003, 32, 373-382; d) H.-L. Yeung, W.-Y. Wong, C.-Y. Yong, H.-L Kwong, Inorg. Chem. 2009, 48, 4108-4117.

[9] a) K. Heinze, K. Hempel, Chem. Eur. J. 2009, 15, 1346-1358; b) B. Jung, A. G. Beck-Sickinger, Angew. Chem. Int. Ed. 1992, 31, 367-486; c) M. Nitz, K. J. Franz, R. L. Maglathlin, B. Imperiali, ChemBioChem 2003, 4, 272-276; d) G. Dirscherl, B. Koenig, Eur. J. Org. Chem. 2008, 597-634.

[10] a) H. W. Hellinga, Curr. Opin. Biotech. 1996, 7, 437-441, b) Y. Lu, J. S. Valentine, Curr. Opin. Struct. Biol. 1997, 7, 495-500; c) L. Rulísek, J. Vondrásek, J. Inorg. Biochem. 1998, 71, 115-127.

[11] a) C. Kaes, A. Katz, M. W. Hossein, Chem. Rev. 2000, 100, 3553-3590; b) W. W. Brandt, Chem. Rev. 1954, 54, 959-1007.

[12] a) M. R. Ghadiri, M. A. Case, Angew. Chem. Int. Ed. 1993, 32, 1594-1597; b) C. A. Pucket, J. K. Barton, J. Am. Chem. Soc. 2009, 131, 8738-8739; c) M. Lieberman, M. Tabet, T. Sasaki, J. Am. Chem. Soc. 1994, 116, 5035-5044; d) T. Koide, M. Yuguchi, M. Kawakita, H. Konno, J. Am. Chem. Soc. 2002, 124, 9388-9389.

[13] a) N. A. Uhlich, P. Sommer, C. Bühr, S. Schürch, J.-L. Reymond, T. Darbre, Chem. Commun. 2009, 41, 6237-6239; b) K. J. Kise, B. E. Bowler, Inorg. Chem. 2002, 41, 379-386; c) S. R. Wilson, A. Yasmin, Y. Wu, J. Org. Chem. 1992, 57, 6941-6945; d) S. L. Fisher, B. Imperiali, J. Am. Chem. Soc. 1993,
115, 8455-8456; e) R. P. Cheng, S. L. Fisher, B. Imperiali, J. Am. Chem. Soc. 1996, 118, 11349-11356.

[14] a) A. Torrado, B. Imperiali, J. Org. Chem. 1996, 61, 8940-8948; b) M. Kyakuno, S. Oishi, H. Ishida, Inorg. Chem. 2006, 45, 3756-3765; c) H. Ishida, Y. Maruyama, M. Kyakuno, Y. Kodera, T. Maeda, S. Oishi, ChemBioChem 2006, 7, 1567-1570; d) H. Ishida, M. Kyakuno, S. Oishi, Pept. Sci. 2004, 76, 69-82; e) M. Kyakuno, S. Oishi, H. Ishida, Chem. Lett. 2005, 34, 1554-1555; f) M. Y. Ogawa, A. B. Gretchikhine, S.-D. Soni, S. M. Davis, Inorg. Chem. 1995, 34, 6423-6424.

[15] a) G. R. Newkome, J. Gross, A. K. Patri, J. Org. Chem. 1997, 62, 3013-3014; b) C. P. Whittle, J. Heterocyclic Chem. 1977, 14, 191-194.

[16] a) J. P. Schneider, J. W. Kelly, J. Am. Chem. Soc. 1995, 117, 2533-2546; b) C. Yu, J. W. Taylor, Bioorg. Med. Chem. 1999, 7, 161-175.

[17] Exploratory modeling studies were performed using the Wavefunction Spartan 10 software using the PM3 semiempirical forcefield. J. P. P. Stewart, J. Comput. Chem. 1989, 10, 209-220.

[18] a) H. E. Stanger, S. H. Gellman, J. Am. Chem. Soc. 1998, 120, 4236-4237; b) S. R. Raghothama, S. K. Awasthi, P. J. Balaram, J. Chem. Soc. Perkin Trans. 2 1998, 137-143; c) B. Imperiali, T. M. Kapoor, Tetrahedron 1993, 49, $3501-3510$.

[19] N. Sewald, H.-D. Jakubke. Peptides: Chemistry and Biology; Wiley-VCH , Weinheim, 2002; 135-256.

[20] In order to reduce the computational cost of the in silico studes, the flanking $\mathrm{N}$-terminal O1Pen and Gly residues were not included in the calculations.

[21] V. Muñoz-Robles, E. Ortega-Carrasco, E.. G. Fuentes, A. Lledós, J.-D. Maréchal, Faraday Discuss. 2011, 148, 137-159.

[22] a) M. Kozísek, A. Svatos, M. Budesínský, A. Muck, M. C. Bauer, P. Kotrba, T. Ruml, Z. Havlas, S. Linse, L. Rulísek. Chemistry (Weinheim an der Bergstrasse, Germany) 2008, 14, 7836-7846; b) J. Alí-torres, J.-D. Maréchal, L. Rodríguez-Santiago, M. Sodupe, J. Am. Chem. Soc. 2011, 133, $15008-15014$.

[23] a) I. Schrodinger. Portland, Oregon, 2000; b) I. Kolossvary, W. C. Guida, J. Am. Chem. Soc. 1996, 118, 5011-5019.

[24] M. Zimmer, Coord. Chem. Rev. 2009, 253, 817-826.

[25] S. Dapprich, I. Komaromi, S. K. Byun, M. Keiji, M. J. Frisch, J. Mol. Struct. THEOCHEM 1999, 461-462, 1-21.

[26] M. J. Frisch, G. W. Trucks, H. B. Schlegel, G. E. Scuseria,; M. A. Robb, J. R. Cheeseman, J. A. Montgomery,.; T. Jr. Vreven, K. N. Kudin, J. C. Burant, J. M. Millam, S. S. Iyengar, J. Tomasi, V. Barone, B. Mennucci, M. Cossi, G. Scalmani, N Rega, G. A. Petersson, H. Nakatsuji, M. Hada, M. Ehara, K. Toyota, R. Fukuda, J. Hasegawa, M. Ishida, T. Nakajima, Y. Honda, O. Kitao, H. Nakai, M. Klene, X. Li, J. E. Knox, H. P. Hratchian, J. B. Cross, V. Bakken, C. Adamo, J. Jaramillo, R. Gomperts, R. E. Stratmann, O. Yazyev, A. J. Austin, R. Cammi, C. Pomelli, J. Ochterski, P. Y. Ayala, K. Morokuma, G. A. Voth, P. Salvador, J. J. Dannenberg, V. G. Zakrzewski, S. Dapprich, A. D. Daniels, M. C. Strain, O. Farkas, D. K. Malick, A. D. Rabuck, K Raghavachari, J. B. Foresman, J. V. Ortiz, Q. Cui, A. G. Baboul, S. Clifford, J. Cioslowski, B. B. Stefanov, G. Liu, A. Liashenko, P. Piskorz, I. Komaromi, R. L. Martin, D. J. Fox, T. Keith, M. A. Al-Laham, C. Y. Peng, A. Nanayakkara, M. Challacombe, P. M. W. Gill, B. G. Johnson, W. Chen, M. W. C. G. Wong, J. A. Pople, Gaussian 092009.

[27] C. J. Wilson, D. Apiyo, P. Wittung-Stafhede. Quart. Rev. Biophys. 2004, 37, 285-314.

[28] A. Göller, U.-W. Grummt, Chem. Phys. Lett. 2000, 321, 399-405.

[29] a) H. Mürner, P. Belser, A. Zelewsky, J. Am. Chem. Soc. 1996, 118, 7989-7994; b) P. Wang, J. E. Miller, L. M. Henling, C. L. Stern, N. L. Frank, A. L. Eckerman, T. J. Meade, Inorg. Chem. 2007, 46, 9853-9862.

Received: ((will be filled in by the editorial staff))

Revised: ((will be filled in by the editorial staff)) Published online: ((will be filled in by the editorial staff)) 